\title{
27 A whole school approach to preventing and managing bullying
}

\author{
Gerald Wurf
}

\section{How to use this policy}

Four decades of research have demonstrated that whole school anti-bullying programs are effective in reducing school bullying and the negative health and wellbeing outcomes associated with victimisation (Farrington \& Ttofi, 2009; Gaffney et al., 2019; Menesini \& Salmivalli, 2017). Effective whole school programs are long-lasting and intensive. They incorporate multilevel strategies to address bullying at the individual student level, as well as preventative strategies targeted at the teacher/classroom level and at the broad level of parents/school community (Ttofi \& Farrington, 2011, Wurf, 2012).

Whole school anti-bullying interventions are underpinned by strong school policies that ensure bullying incidents are managed by restorative approaches (Gregory et al., 2016; Morrison \& Vaandering, 2012) and proportional, authoritative disciplinary consequences (Gaffney et al., 2019; Gerlinger \& Wo, 2016; Ttofi \& Farrington, 2011). Meta-analyses have highlighted that the fair, consistent enforcement of school rules and use of sanctions are key to school safety (Gregory et al., 2010). However, support that incorporates the teaching and reinforcement of pro-social behaviour and the promotion of respectful relationships has been found to be of equal value (Gerlinger \& Wo, 2016). We therefore encourage school leaders and teachers to embrace strategies that have an empirical evidence base and to work with the wider parent body/school community in order to customise and sustain these interventions.

Strong policy represents an ideal starting point for addressing bullying in a systematic and evidence-informed manner. Broad policy consultation is vital to ensure all stakeholders have a voice in framing specific strategies and the restorative and disciplinary actions that address bullying (Smith et al., 2012). Consultation also raises awareness of bullying and informs curriculum and other routine and whole school-based preventative strategies. Transitions, including those at the beginning of the school year, are a time when bullying is known to increase (Espelage et al., 2015). Therefore, times of transition present an ideal opportunity to ensure the school community is informed 
about the school's bullying policy and the preventative and disciplinary approaches that are used to address reports of bullying.

[To adapt and use this policy, delete or modify the text as indicated]

\section{[INSERT name of school] Whole school anti-bullying policy}

\section{Rationale}

Definitions of bullying commonly refer to repetitive actions (i.e., occurring more than once) that cause harm to others and involve a power imbalance such that a victim has difficulty defending themselves (Smith, 2016). Internationally, prevalence rates of bullying vary depending on the measures and definitions that are used. However, large scale self-report survey data continues to suggest that approximately 15 to $30 \%$ of school students report being bullied every few weeks or more often (Jadambaa et al., 2019; Thomas et al., 2017; Skrzypiec et al., 2018). Of note, individual characteristics that set a student apart from the prevailing group are likely to increase the risk of bullying. However, social factors including minority cultural status, sexual/ gender diversity, disability and religious diversity are strongly linked with increased bullying and warrant attention in school anti-bullying interventions (Smith et al., 2012).

School bullying has been found to emerge in the early years of primary school and tends to peak around 11-14 years. Whereas physical bullying declines as students' progress through school, relational, indirect and cyberbullying continues into the final years. Numerous studies have found that boys more often engage in physical bullying; however, gender differences in relational and indirect forms of bullying, such as exclusion, are more difficult to interpret. Females report cyberbullying during early to mid-adolescence, whereas males are more likely to experience higher levels of cyberbullying during late adolescence (Barlett \& Coyne, 2014).

Adverse consequences of bullying have been widely reported in the literature. High-quality data from an Australian population-based study, for example, linked being bullied with markedly increased negative mental health outcomes including higher anxiety, depression, self-harm and suicidal behaviour (Ford et al., 2017). Given this, the need for systematic evidence-based interventions across school populations is imperative.

\section{Purpose}

This policy outlines how a whole school policy requires close collaboration between school leaders, teachers, other school staff, students and parents in order to monitor and prevent bullying. As outlined, extensive empirical evidence now supports the use of whole school approaches to manage bullying. 
Scope

This policy applies to school leaders, teachers and students of [INSERT name of school].

[INSERT specific roles and responsibilities of individuals or teams]

\section{Policy statement}

\section{School management}

[INSERT name of school] has adopted a positive behaviour program and has a clear mechanism for quickly advising parents of alleged instances of bullying that affect their child. The school's disciplinary policy specifies a proportionate range of sanctions for bullying including opportunities for restorative practices (Gregory et al., 2016; Morrison \& Vaandering, 2012). Because peers and parents are more likely to be aware of bullying, and students are traditionally reluctant to inform their teachers/school authorities (Novick \& Isaacs, 2010; Rigby \& Bagshaw, 2003), we actively facilitate reporting by students and parents of alleged bullying occurring at [INSERT name of school]. Accordingly, we take action to investigate allegations of bullying.

Our school management ensures data to capture overall levels of self-reported bullying is collected via school surveys and is shared with the school community. In addition, professional learning opportunities that promote student engagement and wellbeing are supported by school administrators. School counsellors/psychologists are available at the school to support students and their families to peruse interventions to stop bullying.

[INSERT name of school] implements a whole school approach to build an inclusive, positive and supportive school culture.

\section{Teachers}

Teachers at [INSERT name of school] build positive relationships with students and their families. Together with the school leadership team, teachers communicate with families in a timely manner when their child is subject to the school's disciplinary procedures.

Teachers at [INSERT name of school] access published curriculum material and resources (including video material) that is designed to explicitly prevent school bullying from authoritative sources, and they deliver antibullying lessons in our classrooms (Farrington \& Ttofi, 2010; Wurf, 2012). We use opportunities such as school assemblies and parent information evenings to raise awareness of bullying and to promote the school's initiatives to prevent and manage bullying.

Out of classroom supervision and the monitoring of playgrounds and hallways by teachers is undertaken at [INSERT name of school] because these are known places where bullying occurs and adult supervision is associated with 
lower rates of bullying (Ttofi \& Farrington, 2011). An "on-duty" teacher is always available during school hours.

\section{Students}

Classroom behavioural expectations are negotiated with students and expectations make it clear that bullying is not permitted. Students are encouraged and taught to participate in cooperative, group work exercises. A peer support program is active at [INSERT name of school]. Students who provide peer support receive training in the school's anti-bullying policy and the importance of bystander intervention to stop bullying (Polanin et al., 2012). This training includes role plays and opportunities to rehearse bystander pro-social behaviour.

\section{Rating of evidence base}

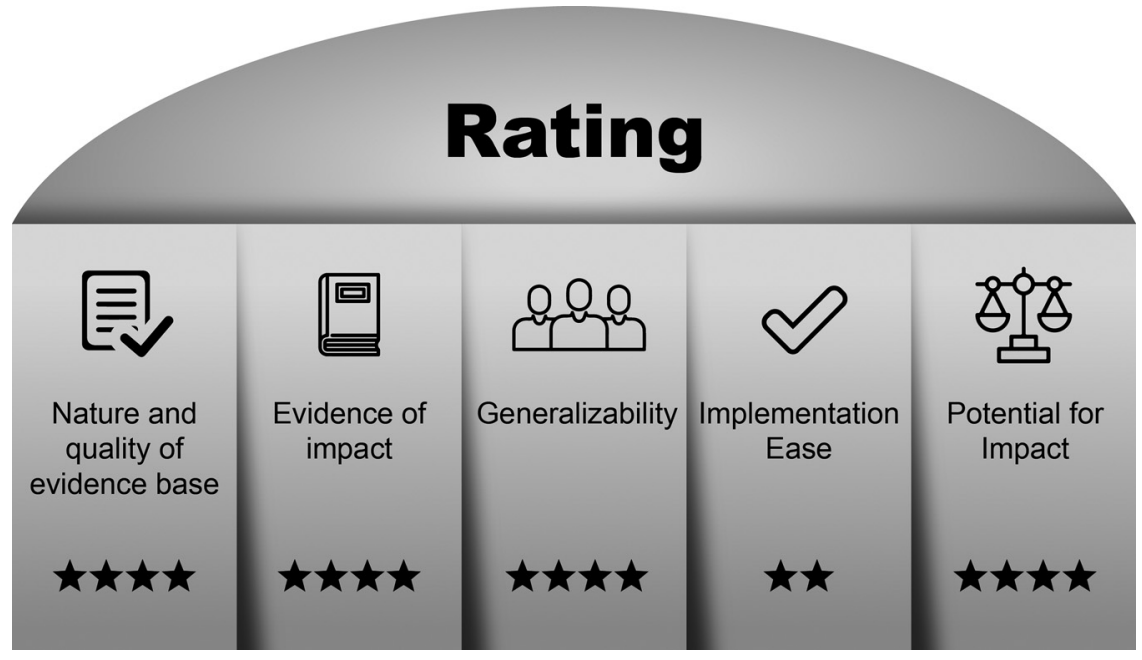

Figure 27.1. A Whole School Approach to Preventing and Managing Bullying Rating of Evidence.

Author Note. Olweus' (1978) seminal work has inspired 40 years of empirical research into programs to prevent school bullying. Recently, Gaffney et al. (2019) synthesised results from robust studies including 45 randomised control trials (RCTs). Whole school anti-bullying programs significantly reduced prevalence rates when compared to control schools $(\mathrm{OR}=1.309 ; 95 \% \mathrm{CI}: 1.24-1.38 ; \mathrm{z}=9.88 ; \mathrm{p}<0.001)$. Significant RCT results have been reported from multiple jurisdictions including Asia, Australia, Europe and North America. Effective programs are long-term, intensive, address multiple levels of intervention and were implemented with a high degree of fidelity across all school years. Although whole school programs are easily embedded, sustained effort is required to ensure practices become routine. School bullying, on average, is reduced by $20-23 \%$ when whole school programs have been evaluated (e.g., Farrington \& Ttofi, 2010; Salmivalli et al., 2011). 


\section{Authorship}

Gerald Wurf, Faculty of Education, Monash University

[INSERT RELEVANT STAFF MEMBERS]

\section{Related policy and documents}

[INSERT RELEVANT POLICY AND DOCUMENTS]

\section{Date of ratification}

This policy was ratified on the [INSERT DATE].

\section{Date of review}

This policy will be reviewed by [INSERT DATE].

\section{References}

Barlett, C., \& Coyne, S. M. (2014). A meta-analysis of sex differences in cyber-bullying behavior: The moderating role of age. Aggressive Behavior, 40, 474- 488.

Espelage, D. L., Hong, J. S., Rao, M. A., \& Thornberg, R. (2015). Understanding ecological factors associated with bullying across the elementary to middle school transition in the United States. Violence and Victims, 30(3), 470-487.

Farrington, D. P., \& Ttofi, M. M. (2009). School-based programs to reduce bullying and victimization. Campbell Systematic Reviews, 6, 1-148.

Ford, R., King, T., Priest, N., \& Kavanagh, A. (2017). Bullying and mental health and suicidal behaviour among 14- to 15-year-olds in a representative sample of Australian children. Australian \& New Zealand Journal of Psychiatry, 51(9), 897-908.

Gaffney, H., Ttofi, M. M., \& Farrington, D. P. (2019). Evaluating the effectiveness of school-bullying prevention programs: An updated meta-analytical review. Aggression and Violent Behavior, 45, 111-133.

Gerlinger, J. \& Wo, J. C. (2016). Preventing school bullying: Should schools prioritize an authoritative school discipline approach over security measures? Journal of School Violence, 15(2), 133-157.

Gregory, A., Clawson, K., Davis, A., \& Gerewitz, J. (2016). The promise of restorative practices to transform teacher-student relationships and achieve equity in school discipline. Journal of Educational and Psychological Consultation, 26, 325-353.

Gregory, A., Cornell, D., Fan, X., Sheras, P., Shih, T. H., \& Huang, F. (2010). Authoritative school discipline: High school practices associated with lower bullying and victimization. Journal of Educational Psychology, 102(2), 483-496.

Jadambaa, A., Thomas, H. J., Scott, J. G., Graves, N., Brain, D., \& Pacella, R. (2019). Prevalence of traditional bullying and cyberbullying among children and adolescents in Australia: A systematic review and meta-analysis. Australian \& New Zealand Journal of Psychiatry, 53(9), 878-888.

Menesini, E., \& Salmivalli, C. (2017). Bullying in schools: the state of knowledge and effective interventions. Psychology, Health \& Medicine, 22(sup1), 240-253. 
Morrison, B. E., \& Vaandering, D. (2012). Restorative justice: Pedagogy, praxis, and discipline. Journal of School Violence, 11(2), 138-155.

Novick, R. M., \& Isaacs, J. (2010). Telling is compelling: The impact of student reports of bullying on teacher intervention, Educational Psychology, 30(3), 283-296.

Olweus, D. (1978). Aggression in the schools: Bullies and whipping boys. Hemisphere Publishing.

Polanin, J. R., Espelage, D. L., \& Pigott, T. D. (2012). A meta-analysis of schoolbased bullying prevention programs' effects on bystander intervention behavior. School Psychology Review, 41(1), 47-65.

Rigby K., \& Bagshaw D. (2003). Prospects of adolescent students collaborating with teachers in addressing issues of bullying and conflict in schools. Educational Psychology, 32, 535-546.

Salmivalli, C., Kärnä, A., \& Poskiparta, E. (2011). Counteracting bullying in Finland: The KiVa program and its effects on different forms of being bullied. International Journal of Behavioral Development, 35(5), 405-411.

Skrzypiec, G., Askell-Williams, H., Slee, P. T., \& Lawson, M. J. (2018). Involvement in bullying during high school: A survival analysis approach. Violence and Victims, $33(3), 563-582$.

Smith, P. K. (2016). Bullying: Definition, types, causes, consequences and intervention. Social and Personality Psychology Compass, 10(9), 519-532.

Smith, P. K., Kupferberg, A., Mora-Merchan, J. A., Samara, M., Bosley, S., \& Osborn, R. (2012). A content analysis of school anti-bullying policies: A follow-up after six years. Educational Psychology in Practice, 28(1), 47-70.

Thomas, H. J., Connor, J. P., Lawrence, D. M., Hafekost, J. M., Zubrick, S. R., \& Scott, J. G. (2017). Prevalence and correlates of bullying victimisation and perpetration in a nationally representative sample of Australian youth. Australian \& New Zealand Journal of Psychiatry, 51(9), 909-920.

Ttofi, M. M., \& Farrington, D. P. (2011). Effectiveness of school-based programs to reduce bullying: A systematic and meta-analytic review. Journal of Experimental Criminology, 7, 27-56.

Wurf, G. (2012). High school anti-bullying interventions: An evaluation of curriculum approaches and the method of shared concern in four Hong Kong international schools. Journal of Psychologists and Counsellors in Schools, 22(1), 139-149. 